\title{
ASO Author Reflections: PCI is Not Predictive of Survival After Complete CRS/HIPEC for High-Grade Appendiceal Primaries
}

\author{
Konstantinos Chouliaras, MD and Konstantinos I. Votanopoulos, MD, Ph.D., FACS \\ Division of Surgical Oncology, Department of General Surgery, Wake Forest Baptist Health, Winston-Salem, NC
}

\section{PAST}

In colon cancer carcinomatosis treated with CRS/ HIPEC, a PCI above 17 is associated with survival that is not different from the survival obtained from best supportive care. ${ }^{1}$ It was unknown to us whether there is a similar PCI limit for HGA primaries, above which even a complete CRS is not offering the patient a survival benefit. ${ }^{2}$

\section{PRESENT}

PCI, either when analyzed at arbitrary cutoff points or as a continuous variable, was not a predictor of survival after complete CRS/HIPEC. Survival was dependent on completion of CRS and not PCI. A CC1 resection in HGA primaries should not be regarded as a complete cytoreduction, because it has similar survival outcomes with a $\mathrm{CC} 2$ resection.

The importance of PCI is it that it can predict in a linear fashion who is the patient who will achieve a CCO resection. In this cohort, only $31 \%$ of the patients with a PCI $\geq 21$ had a complete cytoreduction. ${ }^{3}$ These findings suggest that PCI can be viewed as a key indicator of the ability to achieve a complete resection, which ultimately predicts the ability to affect survival.

ASO Author Reflections is a brief invited commentary on the article, "PCI is Not Predictive of Survival After Complete CRS/HIPEC in Peritoneal Dissemination from High-Grade Appendiceal Primaries". Ann Surg Oncol. 2018;25:674-8.

(C) Society of Surgical Oncology 2018

First Received: 29 October 2018;

Published Online: 12 November 2018

K. I. Votanopoulos, MD, Ph.D., FACS

e-mail: kvotanop@wakehealth.edu
The above analysis was performed categorizing HGA based on Bradley's classification and subgroup analysis of patients with positive nodes, lymphovascular invasion, or signet ring features was not possible. ${ }^{4}$

\section{FUTURE}

The current classification of low- and high-grade appendiceal primaries lumps together tumors with great variability in clinical behavior. This is almost a universal problem for all light microscopy-based classifications or even staging systems. With advances in biomedical engineering and sequencing, we are slowly moving from cohort-based analysis to interactive ex vivo personalized study of patient's individual tumors in the lab. We are currently entertaining for the first time the possibility of a future, that for every patient who presents with appendiceal cancer, we will be able grow its own tumor organoids and decide what is the best course and timing of action in a prospective fashion. ${ }^{5}$

\section{REFERENCES}

1. Goere D, Souadka A, Faron M, et al. Extent of colorectal peritoneal carcinomatosis: attempt to define a threshold above which HIPEC does not offer survival benefit: a comparative study. Ann Surg Oncol. 2015;22(9):2958-64.

2. El Halabi H, Gushchin V, Francis J, et al. The role of cytoreductive surgery and heated intraperitoneal chemotherapy (CRS/HIPEC) in patients with high-grade appendiceal carcinoma and extensive peritoneal carcinomatosis. Ann Surg Oncol. 2012;19(1):110-4.

3. Votanopoulos KI, Bartlett D, Moran B, et al. PCI is not predictive of survival after complete CRS/HIPEC in peritoneal dissemination from high-grade appendiceal primaries. Ann Surg Oncol. 2018;25(3):674-8.

4. Bradley RF, Stewart JH, Russell GB, et al. Pseudomyxoma peritonei of appendiceal origin: A clinicopathologic analysis of 101 patients uniformly treated at a single institution, with literature review. Am J Surg Pathol. 2006;30:551-9.

5. Votanopoulos KI, Shen P, Skardal A, Levine EA. Peritoneal metastases from appendiceal cancer. Surg Oncol Clin N Am. 2018; 27(3):551-61 